\title{
RANKING DECISION MAKING UNITS WITH STOCHASTIC DATA BY USING COEFFICIENT OF VARIATION
}

\author{
F. Hosseinzadeh Lotfi $^{1}$, N. Nematollahi ${ }^{2}$, \\ M.H. Behzadi ${ }^{3}$ and M. Mirbolouki ${ }^{1}$ \\ ${ }^{1}$ Department of Mathematics, Science and Research Branch, Islamic Azad University, \\ Tehran, Iran \\ ${ }^{2}$ Department of Statistics, Faculty of Economics, Allameh Tabataba'i University, \\ Tehran, Iran \\ ${ }^{3}$ Ph.D Student, Department of Statistics, Science and Research Branch, Islamic Azad \\ University, 1477893855, Tehran, Iran, behzadi@srbiau.ac.ir
}

\begin{abstract}
Data Envelopment Analysis (DEA) is a non-parametric technique which is based on mathematical programming for evaluating the efficiency of a set of Decision Making Units (DMUs). Throughout applications, managers encounter with stochastic data and the necessity of having a method that is able to evaluate efficiency and rank efficient units has been under consideration. In this paper considering the concept of coefficient of variation among efficient DMUs, two ranking methods has been proposed. Within these ranking methods, a DMU will have a higher rank if it's coefficient of variation be smaller. These methods are suitable when managers are able to determine weights on coefficient of variations or on inputs and outputs. At the end we applied these methods on a numerical example.
\end{abstract}

Key Words- Coefficient of variation, Data envelopment analysis, Ranking

\section{INTRODUCTION}

In DEA, the efficiency is measured through the comparison process with the efficient frontier. The evaluation of efficiency measure, inorder to rank DMUs seems to be problematic since in a circumstances when efficient units are more than one there will be no further discrimination between these units based on their efficiency scores. This problem is more significant when the number of DMUs relative to the sum of inputs and outputs is small. Many researchers have proposed different methods inorder to rank efficient units [1] [2] [3]. Anderson and Peterson (A.P) [4] proposed a method for ranking efficient units on basis of the position of each eliminated efficient DMUs in relation to its corresponding new Production Possibility Set (PPS). Since in A.P model nonstability can occur, Mehrabian et al. [5] introduced another method (MAJ) for ranking efficient DMUs. This method does not suffer from nonstability but it would be infeasible in some cases.

Variety of DEA models have been formulated for performance evaluation and ranking DMUs in various fields with different data such as: deterministic, interval, fuzzy, etc. In different real world applications managers encounter with data that in which the uncertainty is inherent. In such circumstances the necessity of having a model which has the ability to rank and evaluate the efficiency of DMUs with stochastic data has been under consideration. A model in which DMUs have stochastic data have been defined by Cooper et al. [6] [7] and they have defined the stochastic efficient DMUs. 
The efficiency by stochastic data has been analyzed by Sengupta [8]. In addition Morita et al. [9] have discussed DEA efficiency reliability and probability as being efficient but a suitable model for ranking such DMUs has not been proposed yet.

In this paper in accordance with the useful specifications of coefficient of variation, some indexes for ranking have been defined. These methods consider a multi criteria problem for minimizing coefficient of variation of input and outputs of efficient DMUs. In these methods we use weighting the coefficient of variation regarding the priority of each input and output coefficient of variation or weighting inputs and outputs by managers. Using numerical examples of car manufacturing industry, we will demonstrate how to use the result.

The remainder of paper is organized as follows: First the stochastic DEA models are introduced, Section 3 provides two methods for ranking DMUs with stochastic data. Section 4 and 5 provide an example and conclusion.

\section{STOCHASTIC DEA MODELS}

Let us assume that there exists $\mathrm{n}$, DMUs and $\widetilde{X}_{j}=\left(\widetilde{x}_{1 j}, \ldots, \widetilde{x}_{m j}\right)$ and $\widetilde{Y}_{j}=\left(\tilde{y}_{1 j}, \ldots, \widetilde{y}_{s j}\right)$ are random input and output vectors of $D M U_{j}, j=1 \ldots, n$. These components have been deemed to be normally distributed that $\tilde{x}_{i j}: N\left(\mu_{i j}, \sigma_{i j}^{2}\right)$ and $\tilde{y}_{r j}: N\left(\mu_{r j}^{\prime}, \sigma_{r j}^{\prime 2}\right)$. Chance constrained version of output oriented stochastic CCR model is as follows:

$$
\begin{array}{llr}
\max & \phi & \\
\text { s.t. } & p\left\{\sum_{j=1}^{n} \widetilde{y}_{r j} \lambda_{j} \geq \phi \widetilde{y}_{r o}\right\} \geq 1-\alpha, & r=1, \ldots, s, \\
& p\left\{\sum_{j=1}^{n} \widetilde{x}_{i j} \lambda_{j} \leq \widetilde{x}_{i o}\right\} \geq 1-\alpha, & i=1, \ldots, m, \\
& \lambda_{j} \geq 0, & j=1, \ldots, n .
\end{array}
$$

where in the above models, $p$ means "probability" and $\alpha \in[0,1]$ is a level of error which is a predefined number. In accordance with the definitions and theorems which have been proposed in [7], the above model can be converted into the following deterministic model: 


$$
\begin{aligned}
& \max \varphi+\varepsilon\left(\sum_{r=1}^{s} s_{r}^{+}+\sum_{i=1}^{m} s_{i}^{-}\right) \\
& \text {s.t. } \quad \varphi \mu_{r o}^{\prime}-\sum_{j=1}^{n} \mu_{r j}^{\prime} \lambda_{j}+s_{r}^{+}-\Phi^{-1}(\alpha) \sigma_{r}^{o}(\varphi, \lambda)=0, \quad r=1, \ldots, s, \\
& \sum_{j=1}^{n} \mu_{i j} \lambda_{j}+s_{i}^{-}-\Phi^{-1}(\alpha) \sigma_{i}^{I}(\lambda)=\mu_{i o}, \quad i=1, \ldots, m, \\
& s_{i}^{-} \geq 0, \quad s_{r}^{+} \geq 0, \quad i=1, \ldots, m, \quad r=1, \ldots, s, \\
& \lambda_{j} \geq 0, \quad j=1, \ldots, n \text {. }
\end{aligned}
$$

where:

$$
\left(\sigma_{r}^{o}(\phi, \lambda)\right)^{2}=\sum_{j \neq o} \sum_{k \neq o} \lambda_{j} \lambda_{k} \operatorname{cov}\left(\tilde{y}_{r j}, \tilde{y}_{r k}\right)+2\left(\lambda_{o}-\phi\right) \sum_{j \neq o} \lambda_{j} \operatorname{cov}\left(\tilde{y}_{r j}, \tilde{y}_{r o}\right)+\left(\lambda_{o}-\phi\right)^{2} \operatorname{var}\left(\tilde{y}_{r o}\right),
$$

and

$$
\left(\sigma_{i}^{I}(\lambda)\right)^{2}=\sum_{j \neq o} \sum_{k \neq o} \lambda_{j} \lambda_{k} \operatorname{cov}\left(\tilde{x}_{i j}, \tilde{x}_{i k}\right)+2\left(\lambda_{o}-1\right) \sum_{j \neq o} \lambda_{j} \operatorname{cov}\left(\tilde{x}_{i j}, \tilde{x}_{i o}\right)+\left(\lambda_{o}-1\right)^{2} \operatorname{var}\left(\tilde{x}_{i o}\right) .
$$

Here, $\Phi$ is the cumulative distribution function of the standard normal distribution and $\Phi^{-1}(\alpha)$, is its inverse in level of $\alpha$. The above model is nonlinear programming which can be converted into a quadratic programming model. Cooper et al. [7] have proposed a stochastic efficient $D M U_{o}$ as follows:

DEFINITION- $D M U_{o}$ is stochastic efficient if and only if the following conditions are both satisfied:

(i) $\phi^{*}=1$,

(ii) Slack values are all zeros for all optimal solution.

\section{RANKING DMUS BY USING COEFFICIENT OF VARIATION}

Variance and standard deviation which have been used inorder to dispersal explanation, greatly depend on measurement unit in population. For comparing dispersion between populations, analysts should use indexes which are not related to measurement unit. One of these indexes is coefficient of variation, which is defined as $c=\sigma \mu$ where $\sigma$ and $\mu$ are standard deviation and mean of population, respectively.

One of the application of coefficient of variation is when an identical property in different population, is under measurement but the magnitude of observations differ considerably. For instance, inorder to measure dispersal comparison among profit and loss between high and low technique industries, there will be no alternative at hand but coefficient of variation. Note that in a population when we have a lower coefficient of variation, there will be more stability in performance. 
Let $E$ be the set of all stochastic efficient DMUs and $C_{j}=\left(c_{1 j}, c_{2 j}, \ldots, c_{m j}\right)$ and $C_{j}{ }^{\prime}=\left(c_{1 j}^{\prime}, c_{2 j}^{\prime}, \ldots, c_{s j}^{\prime}\right)$ be the input and output coefficient of variation respectively for every $j \in E$, in a way that:

$$
c_{i j}=\frac{\sigma_{i j}}{\mu_{i j}} \quad, \quad c_{r j}^{\prime}=\frac{\sigma_{r j}^{\prime}}{\mu_{r j}^{\prime}}
$$

\subsection{Method 1- Weighting coefficient of variations}

Considering the concept of coefficient of variation among efficient DMUs, a DMU which its corresponding input and output coefficients of variation are minimum is more desirable and it will have a better rank. Therefore among the efficient DMUs, a DMU will have a better rank if it is the optimal solution of the following problem:

$$
\min _{j \in E}\left\{c_{1 j}, c_{2 j}, \ldots, c_{m j}, c_{1 j}^{\prime}, c_{2 j}^{\prime}, \ldots, c_{s j}^{\prime}\right\}
$$

The above problem is multi criteria problem and for solving such a problem we consider the significance of the magnitude of input and output coefficient of variation, the specific weights can be assigned to these coefficients by managers. For instance in an industrial project the magnitude of coefficient of variation of manpower may be of less importance or the coefficient of variation of consuming material and manufacturing apparatuses be of different importance. Regarding this topic, different weights can be considered for coefficient of variation. Problem (4) can be converted into the following problem:

$$
\min _{j \in E}\left\{\bar{c}_{j}=\sum_{i=1}^{m} v_{i} c_{i j}+\sum_{r=1}^{s} u_{r} c_{r j}^{\prime}\right\}
$$

where $v_{i}, i=1, \ldots, m$ and $u_{r}, r=1, \ldots, s$ are definite weights. We propose $\bar{c}_{j}$ as the ranking index for efficient DMUs.

\subsection{Method 2- Weighting inputs and outputs}

Let us assume that $D_{j}$ be the indicator of inputs and outputs vector when $j \in E$, i.e:

$$
D_{j}=\left(\tilde{x}_{1 j}, \tilde{x}_{2 j}, \ldots, \tilde{x}_{m j}, \tilde{y}_{1 j}, \tilde{y}_{2 j}, \ldots, \tilde{y}_{s j}\right)^{t} .
$$

Also $W \in R^{m+s}$ is the vector of weights which indicates the importance of vector of inputs and outputs. Let $Z_{j}=W^{t} D_{j}, j \in E$. Thus $Z_{j}$ is a stochastic variable which has normal distribution. The coefficient of variation of this variable is a sign of the total coefficient of variation of $D M U_{j}$. Therefore we have:

$$
\begin{gathered}
\mu_{j}^{\prime \prime}=E\left(Z_{j}\right)=W^{t}\left(\mu_{1 j}, \mu_{2 j}, \ldots, \mu_{m j}, \mu_{1 j}^{\prime}, \mu_{2 j}^{\prime}, \ldots, \mu_{s j}^{\prime}\right)^{t}, \\
\sigma_{j}^{\prime \prime 2}=\operatorname{Var}\left(Z_{j}\right)=W^{t} \Sigma W .
\end{gathered}
$$


where $\Sigma$ is the variance-covariance matrix of $D_{j}$. Therefore considering above relations, coefficient of variation of $Z_{j}$ is as follows:

$$
C V_{j}=\frac{\sigma_{j}^{\prime \prime}}{\mu_{j}^{\prime \prime}}, \quad j \in E .
$$

Since $C V_{j}$ are reflecting the extent of constancy in performance of $D M U_{j}$, therefore, the less $C V$ is, more constancy of performance will be and in different settings with more confidence this unit can be considered efficient. Therefore in this method $C V_{j}$ is the index for ranking efficient DMUs. The less this score is, the higher rank of $D M U_{j}$ is.

\section{AN APPLICATION OF RANKING}

A car manufacturing company wants to investigate into the specific car through their factories in different countries and also, to rank the efficient units. For this purpose company consider "production expenses" and "service expenses" as inputs and "acceleration from 0-100" and "the maximum horse power rotation per minute" as outputs. In the opinion of managers each of the inputs and outputs has different significance and priority, where these priorities are predefined from the managers. All the data have normal distribution and they are gathered in tables (1) through (4). These data have been obtained by sampling through ten succeeding temporal period. Also, the results of applying the aforementioned methods in section 3 with two priority vectors are indicated in tables (5) and (6).

Table 1. input 1

\begin{tabular}{lllllllllll}
\hline $\mathbf{X}_{1 \mathbf{j}}$ & period1 & period2 & period3 & period4 & period5 & period6 & period7 & period8 & period9 & period10 \\
\hline x11 & 10037.7 & 9975.7 & 10013.2 & 10032.6 & 9997.5 & 10010.1 & 9973.5 & 10030.3 & 9993.8 & 10045.6 \\
$\mathrm{x} 12$ & 9997.4 & 9964.5 & 9975.2 & 10039.5 & 9977.8 & 9898.5 & 9970.8 & 9987.4 & 9940 & 9999.7 \\
$\mathrm{x} 13$ & 10009.4 & 9991.1 & 10011.3 & 10034.7 & 10044.7 & 10000.6 & 10035 & 10016.5 & 10005.7 & 10030.4 \\
$\mathrm{x} 14$ & 10032.8 & 10006.2 & 10047.2 & 9990.3 & 10026.6 & 10035.6 & 10021 & 10050.8 & 10058.7 & 10029.6 \\
$\mathrm{x} 15$ & 9964 & 10009.1 & 9965.3 & 9938.1 & 9989.8 & 9975.6 & 9970.5 & 9979.2 & 9970.2 & 10053.9 \\
$\mathrm{x} 16$ & 9983.7 & 10008.3 & 10050.6 & 10055.8 & 9994.1 & 9948.3 & 10053.3 & 10075.4 & 10081.2 & 9921.8 \\
$\mathrm{x} 17$ & 10016.5 & 10050.7 & 10030.9 & 10003.9 & 10029.9 & 9998.4 & 10042.3 & 10022.7 & 10044 & 10016.3 \\
$\mathrm{x} 18$ & 10016.8 & 10027.2 & 10038.6 & 10004.6 & 10025.2 & 10032.6 & 9984.7 & 10047.8 & 10017 & 10021.5 \\
$\mathrm{x} 19$ & 9986.6 & 9989.9 & 10015 & 9966.2 & 10059 & 9954.6 & 9976.1 & 9959.8 & 9960.5 & 10000.7 \\
$\mathrm{x} 1,10$ & 9996.7 & 10021.8 & 10023.6 & 10026.3 & 10025.8 & 10009.8 & 10034.4 & 9975 & 10031 & 9999.5 \\
\hline
\end{tabular}


Table 2. input 2

\begin{tabular}{lllllllllll}
\hline $\mathbf{X}_{2 \mathbf{j}}$ & period1 & period2 & period3 & period4 & period5 & period6 & period7 & period8 & period9 & period10 \\
\hline $\mathrm{x} 21$ & 9.2637 & 9.0457 & 8.1849 & 8.9956 & 8.5914 & 9.4166 & 10.0153 & 8.5772 & 9.0778 & 8.8398 \\
$\mathrm{x} 22$ & 9.0915 & 9.8106 & 10.1168 & 9.3509 & 9.395 & 8.2743 & 9.4816 & 9.7766 & 8.973 & 9.7956 \\
$\mathrm{x} 23$ & 10.3774 & 9.9203 & 10.1771 & 10.1969 & 10.2716 & 9.964 & 10.3591 & 9.9601 & 10.1888 & 10.0459 \\
$\mathrm{x} 24$ & 10.3393 & 10.5793 & 10.8264 & 10.1375 & 10.4783 & 10.9337 & 10.9033 & 10.554 & 10.3782 & 10.2801 \\
$\mathrm{x} 25$ & 7.49104 & 7.76119 & 8.41306 & 9.49551 & 9.3203 & 8.5424 & 7.83482 & 8.05882 & 9.74838 & 8.40874 \\
$\mathrm{x} 26$ & 9.2632 & 8.8461 & 8.7745 & 9.5382 & 10.1447 & 7.6051 & 7.9171 & 9.1831 & 9.6143 & 9.7307 \\
$\mathrm{x} 27$ & 10.1729 & 10.5935 & 10.5292 & 10.3275 & 10.6438 & 10.1919 & 10.3315 & 10.4361 & 10.3828 & 10.3722 \\
$\mathrm{x} 28$ & 10.5844 & 10.5381 & 10.4168 & 10.23 & 10.1652 & 10.1414 & 9.8771 & 10.3465 & 10.4199 & 10.5026 \\
$\mathrm{x} 29$ & 8.764 & 10.0621 & 7.7721 & 9.3339 & 7.8466 & 9.8717 & 8.9566 & 10.3985 & 9.9548 & 9.5601 \\
$\mathrm{x} 2,10$ & 10.7033 & 10.5632 & 10.7276 & 10.5324 & 10.7364 & 10.7317 & 10.6693 & 10.8936 & 10.7664 & 10.6915 \\
\hline
\end{tabular}

Table 3. output 1

\begin{tabular}{lllllllllll}
\hline $\mathbf{Y}_{\mathbf{1 j}}$ & period1 & period2 & period3 & period4 & period5 & period6 & period7 & period8 & period9 & period10 \\
\hline $\mathrm{y} 1,1$ & 11.3021 & 11.3748 & 11.2201 & 11.144 & 11.3548 & 11.5313 & 11.6184 & 12.0096 & 11.1365 & 11.5129 \\
$\mathrm{y} 1,2$ & 11.1543 & 11.6795 & 11.9251 & 11.443 & 10.572 & 9.9516 & 11.0554 & 11.6893 & 11.11 & 11.214 \\
$\mathrm{y} 1,3$ & 9.8729 & 10.5942 & 9.1735 & 10.3173 & 9.9395 & 10.3133 & 9.2206 & 9.6419 & 9.7899 & 10.2297 \\
$\mathrm{y} 1,4$ & 9.6855 & 9.6424 & 9.2758 & 9.6589 & 9.8589 & 10.6956 & 9.1564 & 9.7087 & 8.8202 & 9.0603 \\
$\mathrm{y} 1,5$ & 11.2969 & 11.8646 & 11.6855 & 11.7956 & 11.5162 & 12.2677 & 11.7501 & 12.2583 & 12.4484 & 12.4793 \\
$\mathrm{y} 1,6$ & 11.4075 & 11.2272 & 12.1297 & 11.7059 & 11.9491 & 10.7108 & 11.4051 & 10.6782 & 11.8115 & 11.2247 \\
$\mathrm{y} 1,7$ & 9.8929 & 9.9607 & 9.8242 & 10.2438 & 10.1394 & 9.9547 & 9.6843 & 9.6536 & 10.0772 & 10.2146 \\
$\mathrm{y} 1,8$ & 9.4471 & 10.2223 & 9.5851 & 10.1988 & 8.8077 & 10.0335 & 9.5656 & 10.1492 & 9.6211 & 10.081 \\
$\mathrm{y} 1,9$ & 10.2396 & 12.146 & 11.1536 & 11.2986 & 13.06 & 9.6666 & 11.5222 & 12.7845 & 11.2119 & 9.7935 \\
$\mathrm{y} 1,10$ & 9.4981 & 10.0259 & 10.2198 & 10.1127 & 10.3899 & 10.0516 & 10.0384 & 9.8584 & 10.1073 & 10.1583 \\
\hline
\end{tabular}

Table 4. output 2

\begin{tabular}{lllllllllll}
\hline $\mathbf{Y}_{2 \mathbf{j}}$ & period1 & period2 & period3 & period4 & period5 & period6 & period7 & period8 & period9 & period10 \\
\hline y2,1 & 101.275 & 111.112 & 90.201 & 91.966 & 97.173 & 102.852 & 92.352 & 97.614 & 108.875 & 75.223 \\
y2,2 & 109.991 & 76.782 & 98.868 & 106.237 & 113.742 & 100.53 & 110.048 & 109.818 & 99.717 & 111.298 \\
y2,3 & 96.543 & 99.523 & 93.344 & 92.3 & 98.721 & 103.952 & 97.838 & 100.284 & 106.861 & 97.419 \\
y2,4 & 96.817 & 103.021 & 100.573 & 98.677 & 101.011 & 95.643 & 100.901 & 93.696 & 94.981 & 96.382 \\
y2,5 & 104.824 & 100.503 & 105.669 & 108.393 & 105.082 & 96.15 & 113.406 & 98.767 & 115.951 & 101.475 \\
y2,6 & 99.248 & 108.436 & 103.164 & 107.006 & 101.37 & 105.586 & 99.725 & 109.767 & 111.135 & 110.741 \\
y2,7 & 101.609 & 99.111 & 95.57 & 100.26 & 103.218 & 93.401 & 100.692 & 93.687 & 101.054 & 106.32 \\
y2,8 & 97.019 & 102.656 & 101.899 & 103.57 & 96.333 & 102.167 & 99.911 & 101.06 & 102.101 & 97.597 \\
y2,9 & 99.945 & 88.252 & 100.557 & 114.821 & 100.185 & 92.762 & 99.854 & 94.439 & 103.795 & 103.499 \\
y2,10 & 96.947 & 99.849 & 96.071 & 99.328 & 104.453 & 96.836 & 94.87 & 103.566 & 98.573 & 91.013 \\
\hline
\end{tabular}


Table 5. results of method 1

\begin{tabular}{c|ccc||c|ccccc}
\hline & $\boldsymbol{\alpha}=\mathbf{0 . 0 5}$ & \multicolumn{7}{|c}{$\boldsymbol{\alpha}=\mathbf{0 . 1}$} \\
\hline Efficient DMU & DMU1 & DMU2 & DMU6 & Efficient DMU & DMU1 & DMU2 & DMU5 & DMU6 DMU10 \\
\hline $\bar{C}(1)$ & 0.0449 & 0.0555 & 0.0378 & $\bar{C}(1)$ & 0.0449 & 0.0555 & 0.0391 & 0.0378 & 0.0218 \\
\hline rank & 2 & 3 & 1 & rank & 4 & 5 & 3 & 2 & 1 \\
\hline $\bar{C}(2)$ & 0.179 & 0.2055 & 0.1701 & $\bar{C}(2)$ & 0.179 & 0.2055 & 0.1784 & 0.1701 & 0.0716 \\
\hline rank & 2 & 3 & 1 & rank & 4 & 5 & 3 & 1 & 2 \\
\hline
\end{tabular}

Table 6. results of method 2

\begin{tabular}{|c|c|c|c|c|c|c|c|c|c|}
\hline \multicolumn{4}{|c|}{$\alpha=0.05$} & \multicolumn{6}{|c|}{$\alpha=0.1$} \\
\hline Efficient DMU & DMU1 & DMU2 & DMU6 & Efficient DMU & DMU1 & DMU2 & DMU5 & DMU6 & DMU10 \\
\hline$C V(1)$ & 0.002 & 0.004 & 0.0052 & $C V(1)$ & 0.002 & 0.004 & 0.0028 & 0.0052 & 0.0018 \\
\hline rank & 1 & 2 & 3 & rank & 2 & 4 & 3 & 5 & 1 \\
\hline$C V(2)$ & 0.162 & 0.3223 & 0.4147 & $C V(2)$ & 0.162 & 0.3223 & 0.2215 & 0.4147 & 0.1423 \\
\hline rank & 1 & 2 & 3 & rank & 2 & 4 & 3 & 5 & 1 \\
\hline
\end{tabular}

Note that in Table (5), $\bar{c}_{j}(1)$ and $\bar{c}_{j}(2)$ are the sum of the aggregated coefficient of variation which are gained from expression (4) with weight vectors $(u, v)_{1}=(0.2,0.1,0.4,0.3)$ and $(u, v)_{2}=(1,1,1,1)$, respectively. In Table (6), $C V_{j}(1)$ and $C V_{j}(2)$ are gained from expression (5) with weight vectors $W_{1}=(0.25,0.05,0.45,0.25)$ and $W_{2}=(1,1,1,1)$, respectively.

\section{CONCLUSION}

Through applications, number of efficient units are more than one. Therefore managers want to find a suitable and analytical method inorder to rank efficient units. In many setting we encounter with stochastic data. Therefore in this paper two different methods for ranking efficient units with stochastic data are proposed. In these methods according to the useful characteristic of coefficient of variation, some indexes for ranking have been defined. These methods are applicable for situations in which some of the input and output coefficient of variation are significant for managers. For instance, when lifetime of a part, product quality, consumer satisfaction and etc. are important. For purpose of illustrations the aforesaid methods in car manufacturing industry are considered. The mentioned methods are based on weighting the coefficient of variation as the criteria of the problem. This weighting method is one of the methods for solving multi criteria problem. Other methods can be suggested for further investigations. 


\section{REFERENCES}

1. F. Liu, and H. H. Peng, Ranking of units on DEA frontier with common weights, Computer and Operation Research 35, 1524-1537, 2008.

2. T. Obata, and H. Ishii, A method of discriminating efficient candidates with ranked voting data, European Journal of Operational Research 131, 233-237, 2008.

3. A. Charnes, W. W. Cooper, and E. Rhodes,Measuring the efficiency of decision making units, European Journal of Operational Research 2, 429-444, 1978.

4. P. Andersen, and N. C. Petersen, A procedure for ranking efficient units in data envelopment analysis, Management Science 39, 1261-1264, 1993.

5. S. Mehrabian, M. R. Alirazaei, and GR. Jahanshahloo, A complete efficiency ranking of decision making units: an application to the teacher training university, Computational Optimization and Application 14, 1998.

6. W.W. Cooper, Z. Huang, and S. Li, Satisfying DEA models under chance constraints, The Annals of Operations Research 66, 279-295, 1996.

7. W.W. Cooper, H. Deng, Z. Huang, and S. X. Li , Chance constrained programming approaches to congestion in stochastic data envelopment analysis, European Journal of Operational Research 155, 487-501 155, 2004.

8. JK. Sengupta, Efficiency analysis by stochastic data envelopment analysis, Applied Economics Letters 7, 379-383, 2000.

9. H. Morita, and L. M. Seiford, Characteristics on stochastic DEA efficiencyreliability and probability being efficient, Journal of Operations Research Society of Japan 42, 389-404, 1999. 